\title{
Gastronomia do Amazonas: percepção dos permissionários da Praia do Tupé, Manaus, AM
}

\section{Gastronomy of Amazonas: perception of licensed sellers from Tupé Beach, Manaus, AM (Brazil)}

\author{
Ana Celina Xavier de Lira ${ }^{1}$ \\ Helen Rita Menezes Coutinho ${ }^{2}$ \\ Marklea da Cunha Ferst ${ }^{3}$
}

\begin{abstract}
Resumo - O objetivo geral da pesquisa foi identificar a identidade gastronômica da praia do Tupé que faz parte da Reserva de Desenvolvimento Sustentável (RDS) do Tupé, localizada em Manaus, Amazonas (AM), de acordo com a perspectiva dos permissionários autorizados a vender comida no local. Como metodologia utilizou-se o método dedutivo, quantitativo, com pesquisa pura, descritiva, exploratória e explicativa. Trata-se de pesquisa bibliográfica e de campo da qual participaram cinco permissionários autorizados a vender alimentos na praia do Tupé. O estudo foi realizado com técnicas de observação direta por intermédio de observação e utilização de formulários para entrevistas no período entre abril e maio de 2018. Constatou-se que os permissionários estavam trabalhando em barracas improvisadas e que a infraestrutura gastronômica fornecida pelo Estado ainda não havia sido liberada para utilização. A pesquisa permitiu averiguar a pouca identidade dos permissionários com a cultura gastronômica do Amazonas. Foi identificada pouca identidade com outros produtos regionais além do peixe, o que pode se dar em virtude da baixa escolaridade e falta de interesse em pesquisar e conhecer sobre os produtos regionais. Segundo a percepção dos permissionários, mesmo servindo carne bovina e frango, entendem ser o peixe, de todos os alimentos servidos, o que representa a gastronomia regional da Amazônia. Foi observado nos permissionários pouco conhecimento sobre os produtos regionais que podem ser utilizados no manejo dos alimentos, bem como as dificuldades elencadas pelos mesmos, como falta de infraestrutura e logística para compra dos insumos.
\end{abstract}

Palavras-chave: Turismo. Cultura. Identidade. Gastronomia. Amazonas.

\footnotetext{
${ }^{1}$ Bacharel em Turismo pela Universidade do Estado do Amazonas (UEA).

E-mail: anacelinalira@gmail.com
}

\footnotetext{
${ }^{2}$ Mestre em Administração pela Universidade Federal de Santa Catarina (UFSC). Bacharel em Turismo pela Universidade de Fortaleza (UNIFOR). Doutoranda em Turismo e Hotelaria pela Universidade do Vale do Itajaí (UNIVALI). Doutoranda em Educação pela Universidad de La Empresa (UDE). Professora Assistente da Universidade do Estado do Amazonas (UEA). E-mail: hcoutinho@uea.edu.br

${ }^{3}$ Mestre em Direito das Relações Sociais pela Universidade Federal do Paraná (UFPR). Doutoranda em Turismo e Hotelaria pela Universidade do Vale do Itajaí (UNIVALI). Bacharel em Direito pela Universidade Tuiuti do Paraná (UTP). Professora Assistente da Universidade do Estado do Amazonas (UEA).E-mail: mferst@uea.edu.br
} 


\begin{abstract}
The general objective of this research was to identify the gastronomic identity of Tupé Beach, which is part of the Sustainable Development Reserve (RDS) of Tupé, located in Manaus, Amazonas, Brazil, according to the perspective of the licensed sellers authorized to sell food at this place. As a methodology, the deductive method was used, with quantitative, pure, descriptive, exploratory and explanatory research. This is a bibliographic and field research, in which five licensed sellers authorized to sell food at Tupé Beach participated. The study was carried out with direct observation techniques using observation and interview forms in the period from April to May, 2018. It was found that the licensed sellers were working in improvised tents and that the gastronomic infrastructure provided by the State had not yet been released for their use. The research made it possible to ascertain the lack of identity of these sellers with the Amazonas gastronomic culture. Little identity has been identified with other regional products other than fish, which may be due to low education and lack of interest in in researching and knowing about the regional products. According to the licensed sellers' perception, despite serving beef and chicken, they understand that it is the fish, of all the foods served, which represents the regional gastronomy from Amazonas. Little knowledge about regional products that can be used in food handling was observed, as well as the difficulties listed by them, such as lack of infrastructure and logistics for purchasing inputs and products.
\end{abstract}

Keywords: Tourism. Culture. Identity. Gastronomy. Amazonas. 


\section{INTRODUÇÃO}

Considerada como um importante atrativo cultural de um lugar, a gastronomia é um produto turístico cada vez mais valorizado (HENRIQUE e CUSTÓDIO, 2010). As circunstâncias em relação à comida levam as pessoas a um aprendizado desde seu nascimento. Elas já nascem com fome e aprendem que a alimentação é imprescindível para seu fortalecimento. No entanto comer está além de saciar a fome. A comida e o ato de comer estão vinculados ao aprendizado social por ser vital a vida. Como afirma Schlüter (2003, p. 13), “a alimentação é um processo consciente e voluntário que se ajusta a diferentes normas segundo cada cultura, e no qual o ser humano é socializado desde o seu nascimento". A gastronomia além de ser arte na cozinha moderna, também vem sendo utilizada como oferta para o turismo, não obstante ao simples ato de saciar a fome dos turistas, mas como parte significante de intercambiar a cultura do local visitado.

Nesse contexto, identifica-se que a culinária amazônica tem grande representatividade na cultura brasileira, o que para o turismo cultural torna-a um valioso destino turístico. (QUINZANI, CAPOVILLA E CORRÊA, 2016). O objeto dessa pesquisa tem como foco a identidade da culinária oferecida na praia do Tupé, que está inserida na Reserva de Desenvolvimento Sustentável (RDS) do Tupé. A praia em questão possui areia branca banhada pelas águas do Rio Negro, formando uma paisagem cênica que atrai visitantes para o local. Para ofertar a alimentação aos visitantes, o Estado concedeu licenças e infraestrutura (barracas) para que os permissionários pudessem desenvolver esta atividade econômica.

Os residentes desta RDS são compostos por famílias tradicionais e famílias indígenas que encontraram na atividade turística o modo de manter suas tradições e costumes, atraindo diversos visitantes, principalmente nos finais de semana. Considerando que a gastronomia da praia do Tupé é ainda modesta como atrativo turístico, surgiu a necessidade de uma investigação científica para entender as razões pelas quais o serviço gastronômico não é um dos principais motivos da visita dos turistas e visitantes. Diante da análise da contextualização em tela, apresenta-se o seguinte questionamento: qual a identidade gastronômica que é apresentada aos turistas e visitantes da praia do Tupé, segundo a percepção dos barraqueiros (permissionários)? 
Para compreender a percepção dos barraqueiros e a identidade gastronômica local foram estabelecidos os seguintes objetivos específicos: traçar o perfil dos permissionários da praia do Tupé; relatar as características gerais da gastronomia cultural na praia do tupé segundo a percepção dos barraqueiros permissionários; analisar se a gastronomia local representa a identidade gastronômica do Amazonas, e descrever as dificuldades que esses permissionários encontram para desenvolver as atividades gastronômicas no local, já que recebe turistas e visitantes.

Assim, a pesquisa contribuirá para futuras adaptações no cardápio ofertado, e para que os permissionários possam compreender a importância cultural da gastronomia amazonense como produto turístico.

\section{GASTRONOMIA COMO IDENTIDADE CULTURAL}

Ao mesmo tempo em que a refeição satisfaz uma necessidade humana essencial, percebe-se que ela também é uma maneira de reforçar as relações sociais, a convivialidade e sociabilidade ou, inclusive, uma experiência (BOER; REJOWSKI, 2016). A gastronomia não pode ser vista isoladamente, pois envolve diversos fatores, tangíveis ou intangíveis, que ocorrem ao mesmo tempo formando uma experiência.

Para Araújo et al. (2005, p. 15) “a gastronomia é a história cultural da alimentação. Sua essência é a mudança, a temporalidade, a visão de passado como processo contínuo de perspectiva sobre tendências, sobre o constante e o eventual". Dentro do contexto turístico é fundamental e necessário entender a gastronomia como manifestação cultural, uma vez que a alimentação e as bebidas e todo o processo a eles vinculados extrapolaram o universo da oferta técnica e se consolidaram como oferta original e diferencial de um destino (GIMENES-MINASSE, 2016).

A cultura alimentar é estabelecida pelos hábitos alimentares de forma que a tradição e a inovação tem a mesma importância, principalmente no que diz respeito aos nossos hábitos cotidianos, que são compostos pelo que é tradicional e pelo que se constituem como novos hábitos (BRAGA, 2004, p. 39). O desenvolvimento da gastronomia está relacionado à função social das refeições que são um momento de troca, de prazer, de socialização e comensalidade, que é a existência de vínculos e obrigações mútuas entre os que comem e bebem juntos (BRAUNE; FRANCO, 2013, p. 
13). Concordando com o autor, entende-se que a gastronomia assim como as tantas outras técnicas do homem, é uma arte que transmite prazer e contentamento.

Dentz (2011, p. 2) enfatiza que "a gastronomia é parte integrante da cultura nas diferentes sociedades, tornando-se representação e/ou traço cultural marcante enquanto um resultado das características étnicas, crenças e valores dos muitos grupos humanos", ou seja, a gastronomia é uma arte expressa, é a marca e identidade de caracterização de um povo. Entende-se que a gastronomia é o conjunto de simbolismo, crenças e valores que identificam as singularidades de certo grupo social. Por meio do contato com povos ou grupos sociais diferentes e pela comensalidade o homem faz a troca de suas experiências e transmite seus valores e suas preferências.

De acordo com Rodrigues et al. (2015, p. 2),

Entende-se que todos os atos, particularidades e características servem para identificar um povo e a sua cultura, de modo a propiciar que sejam identificados em qualquer lugar ou a qualquer tempo. Deve-se olhar para o passado para entender todo o processo de formação da identidade de um povo através da gastronomia, e a sua importância para que eles possam se consolidar na história.

Rodrigues et al. (2015) acredita que a gastronomia seja uma forma de linguagem cultural descrita por meio do local e de seus moradores. A gastronomia ou a culinária são elementos intrínsecos à identidade de um povo. Destaca-se que por meio da gastronomia típica, ao se alimentar em determinado lugar é possível viajar no tempo, trazer à memória sensações antigas ligadas a lembranças de um lugar e sentir experiências únicas. A identidade, segundo Dentz (2011), está diretamente ligada à memória e pode ser entendida como aspectos simbólicos de um determinado povo, como suas crenças, ritos e experiências comuns.

A gastronomia quando está associada ao turismo se revela um instrumento importantíssimo para manutenção e conservação, uma vez que atua como condutor da cultura popular, e auxilia na "construção e permanência das identidades gastronômicas dos povos [...]" (DENTZ, 2011, p. 48). Além disso, a gastronomia “é um motivador real de fluxos turísticos, e que através do reconhecimento, organização e potencialização do legado gastronômico de um lugar, é possível atingir um nível apropriado de diversificação do produto turístico". (AZEVEDO; SILVEIRA, 2016, p. 16). MinasseGimenes (2014) corrobora ao afirmar que a gastronomia é um atrativo turístico 
propriamente dito, motivando o turista a fazer o turismo gastronômico, o que revela a complexidade e proficuidade do relacionamento entre gastronomia e atividade turística.

\section{TURISMO GASTRONÔMICO E IDENTIDADE AMAZÔNICA}

Dentro da atividade turística, vários segmentos são utilizados para o seu fomento, e os patrimônios culturais material e imaterial podem se constituir uma importante ligação entre o turismo e a cultura. Entende-se que patrimônio cultural diz respeito ao conjunto de bens de valor material e imaterial, que para determinada sociedade tem sua importância com significado e valores, a qual ao longo de sua história foi se estabelecendo (HENRIQUE; CUSTÓDIO, 2015, p. 72).

Em conformidade com as motivações do turista, muitos destinos turísticos têm buscado no turismo cultural uma forma de se diferenciar de seus concorrentes. Pois como afirma Pérez (2009, p. 109), o "turismo cultural é uma vivência de participação em novas e profundas experiências culturais estéticas, intelectuais, emocionais e psicológicas". E quanto mais bem elaborado o roteiro cultural mais fácil de alcançar as expectativas do turista.

Uma iguaria ou uma bebida pode ser objeto de uma deliciosa degustação, uma experiência única, mas também pode ser considerada como uma forma de conhecer ingredientes, formas de preparo, tradições e valores locais. Partindo desse contexto cultural em que o patrimônio gastronômico ganha força e importância como atrativo turístico, quanto mais autêntico e ligado ao contexto visitado, maior será seu poder de atração (MINASSE-GIMENES, 2014).

A gastronomia de um local se apresenta como alternativa para impulsionar a oferta turística, e como segmento do turismo cultural promove a gastronomia como mais que uma simples arte de cozinhar, mas como importante intercâmbio da cultura popular.-(SANTOS; ANTONINI, 2018).

Dessa forma, afirma-se que turismo e a gastronomia são intrínsecos, pois não se pode planejar a atividade sem pensar na alimentação do turista por ser um item básico, e a gastronomia local também é um atrativo para o turismo cultural. A gastronomia (especialmente a típica), vem se destacando no turismo cultural, não simplesmente por constituir um bem cultural, a qual precisa ser valorizada como os demais segmentos, 
mas sim por proporcionar ao turista um importante ponto de contato com a realidade local visitada, fazendo-o degustar no sentido figurado e literal, seus ritos, valores e tradições locais. Ansarah e Nunes (2007) corroboram ao afirmarem que por existir uma grande variedade de culturas, a comida brasileira está se tornando um novo atrativo turístico para diversas cidades. Um exemplo desta afirmação pode ser percebida quando os turistas pensam em viajar para o Sul do Brasil e lembram-se de chocolate as primeiras cidades a serem lembradas são Gramado e Canela, uma vez que são cidades conhecidas pelas fabricas de chocolate e doces, além do famoso café colonial (ANSARAH; NUNES, 2007).

Deve-se ressaltar, porém, que muitas vezes o atrativo tem como cerne as comidas e bebidas tradicionais. Gimenes (2009, p. 9) destaca que:

\footnotetext{
Estas iguarias, preparadas ao longo dos tempos e integrantes da cultura imaterial de suas respectivas comunidades, destacam-se em meio ao horizonte das comidas padronizadas que prevalece nos grandes centros urbanos, e muitas vezes se tornam uma possibilidade de conexão cultural ou com um estilo de vida que se deseja recuperar ou alcançar, potencializando a atratividade destas localidades.
}

Assim, cada povo possui uma culinária distinta na qual reflete muitos aspectos da sociedade, como características geográficas, climáticas, culturais, sociais e econômicas. Considerando tais elementos, o homem faz adaptações ao meio que se insere.

Cada região do país tem sua peculiaridade, devido às diferenças de clima, tipo de solo, vegetação, relevo e povos. A gastronomia Amazônica, apesar das influências que recebeu, apresenta em sua maioria dos pratos típicos a marca da identidade indígena por meio de ingredientes típicos da região, principalmente a mandioca.

Boa parte da cultura à mesa na região vem do legado indígena, que expeliu seu conhecimento aos livros de receitas escritos. É considerada por muitos o maior exemplo de culinária tipicamente nacional. Apesar de suas raízes amazônicas, a cozinha regional sofreu influência forte de imigrantes portugueses, logo no início da colonização. Depois, com o ciclo da borracha, outros povos chegaram e deixaram seus traços na culinária, como é o caso de libaneses, japoneses, italianos e até mesmo os próprios nordestinos que migraram para a região nesse mesmo período (BRASIL, 2013, p.18).

De acordo com a revista Aromas Cores e Sabores do Brasil do Ministério da Cultura, os principais ingredientes que caracterizam a Amazônia são: 
mandioca, cupuaçu, açaí, pirarucu, filhote, urucum (açafrão brasileiro), jambú, guaraná, tucunaré, castanha-do-Pará, tucupi, farinhas; queijo do Marajó, pimentas; feijões". (...) [E dentre os pratos desta região estão:] "Pato no Tucupi, Tacacá (caldo quente servido com tucupi, camarão seco, jambú e goma de tapioca), Maniçoba (a feijoada paraense - folhas da mandioca cozidas por sete dias e servidas com carne suína), Pirarucu de casaca (pescado com farinha) (BRASIL, 2013, p. 18).

A gastronomia do Amazonas é originária da culinária indígena, e apesar da influência culinária de outros povos, a população local permaneceu com a tradição de consumir alimentos e bebidas típicas da região. Enfatizando a importância da mandioca na culinária amazonense como herança alimentar dos índios, destacam-se alguns dos derivados (HIGASHI; MARTINS, 2013). Dentre eles há o tucupi usado como molho e caldo, a goma e o polvilho, que são utilizados no preparo de beijus e tapioca, farinha de tapioca, os biscoitos da Amazônia - beiju-cica, beiju-assú, beiju-puqueca e beijumembeca (BRAGA 2004, p. 109). Além do peixe e da carne de caça que sempre foi mais evidente no interior, pois nunca deixou de ser apreciada pelo caboclo, e os pratos a partir de quelônios (tartaruga e tracajá) que são iguarias que quebram a rotina de pescado, especialmente no interior do Estado, a culinária amazonense recebeu influências externas (SILVA, 2005).

A culinária amazonense caracteriza-se pela sua peculiariedade, de traços fortes e originais que difere da gastronomia de outras regiões. Dantas $(2013$, p.1) destaca que um programa tradicional dos manauenses nos domingos pela manhã, "é a ida aos cafés regionais levar os consumidores a se deliciar com os sabores da terra. No cardápio, estes locais oferecem desde produtos típicos da região amazônica como tucumã e tapioca, aos tradicionais bolos de chocolate e café com leite". No cardápio pode ser encontrado o tradicional X-Caboquinho (sanduíche feito com pão francês, queijo coalho, tucumã e banana frita), a tapioca (com coco, com leite condensado, com castanha do Brasil e/ou com queijo coalho), banana pacovã frita, pupunha, os tubérculos como o cara-roxo e macaxeira cozida, além de ovos cozidos, fritos e farofa de charque (esta, se deve a influências dos nordestinos). As bebidas de acompanhamento que são servidas, se dão pelos sucos de maracujá, taperebá e o cupuaçu, além do tradicional café com leite.

De acordo com Costa et al. (2013, p. 64), a pesca é o alicerce da economia na região amazônica, esta não só se destaca, em relação às demais regiões brasileiras, pela riqueza de espécies exploradas, mas também, pela quantidade de pescado capturado 
anualmente, e nas refeições como almoço e jantar os peixes são bastante explorados. Os mais utilizados são o tambaqui, pirarucu, pacu, jaraqui e matrinchã (PORTAL AMAZÔNIA, 2020).

O tambaqui é um peixe muito popular nos restaurantes de Manaus. Seus principais pratos são: a caldeirada de tambaqui que é temperada com limão, sal, alho, tomate, pimentão, pimenta-de-cheiro e cheiro verde e servido com pirão; tambaqui assado na brasa em bandas; e costela de tambaqui frito. Geralmente eles são servidos acompanhado de arroz branco ou baião de dois, farofa ou farinha e a popular salada vinagrete (CLEMENT; FALCÃO; SOUZA, 2010, p. 39).

Outro peixe popular muito utilizado na gastronomia amazonense é o pirarucu, que possui uma carne singular. Este peixe ficou conhecido como "bacalhau da Amazônia”. Dentre as diversas receitas à base de pirarucu, destacam-se: filé de pirarucu à milanesa, "[...] pirarucu na brasa, pirarucu no leite de coco e pirarucu-de-casaca. Geralmente é acompanhado por arroz, farofa e molho-de-pimenta" (CLEMENT; FALCÃO; SOUZA, 2010, p. 22).

O tucunaré também é outro peixe de referência no Estado do Amazonas, pois possui uma carne tenra. Os principais pratos com base neste peixe são: a caldeirada de tucunaré que é muito tradicional tanto na capital quanto no interior; e o escabeche, que é feito frito ou assado e depois cozido temperado com limão, sal, alho, tomate, pimentão, pimenta-de-cheiro e cheiro verde (CLEMENT; FALCÃO; SOUZA, 2010, p.54).

O jaraqui é um dos vários peixes da Amazônia, ele é consumido na maioria das vezes frito, acompanhado de farofa, baião-de-dois e molho-de-pimenta. “[...] no entanto, pode ser preparado assado, cozido, e até em suflê" (CLEMENT; FALCÃO; SOUZA, 2010, p. 59); E por último, a matrinchã, peixe de carne considerada muito saborosa, que na maioria das vezes é preparada assada na brasa ou no forno recheada (com verduras), com as escamas (CLEMENT; FALCÃO; SOUZA 2010, p. 57).

Tartarugas e outros quelônios como por exemplo o tracajá, têm sido caçados, pescados e seus ovos colhidos há muitas gerações na Amazônia. A carne é considerada uma iguaria da culinária local (FERRARINI, 1980; REDFORD \& ROBINSON, 1991). Vale destacar que é permitido legalmente o consumo de quelônios desde que seja oriundo de criadouros ou áreas de manejo. 
Dentre as frutas, destacam-se o cupuaçu e o tucumã que estão diariamente no cardápio de restaurantes e de muitas famílias na região. O cupuaçu é um símbolo amazônico pela sua notoriedade e singularidade. O tucumã, diferente do cupuaçu, é pequeno e tem um caroço que ocupa quase todo o tamanho do fruto, coberto por uma fina polpa oleosa. O tucumã é descascado e geralmente consumido puro com bocadas de farinha - termo local usado para especificar quando o indivíduo pega a farinha com a mão e joga diretamente a boca - principalmente no interior do Amazonas, e acompanhado por café (CLEMENT; FALCÃO; SOUZA 2010, p.148-165).

A gastronomia do Amazonas tem o seu diferencial, com as influências do passado tenham deixado sua contribuição e a "gourmetização" 4 de pratos nos restaurantes da contemporaneidade. O sabor e a tradição alimentar desta região em sua maioria podem ser considerados muito autêntica, uma vez que conserva as receitas tradicionais.

Desta forma, entende-se que a gastronomia local é histórica e é inegável as contribuições para a compreensão das manifestações culturais como identidade cultural, representada por recursos e ingredientes disponíveis, momentos de escassez e abundância, crenças, costumes, ritos e expressões culturais de um grupo que se reconhece nesses aspectos, e partilha do mesmo sentimento de pertencer a uma nação ou região, passados de geração para geração. (ANDRADE, 2018).

\section{METODOLOGIA}

Quanto aos procedimentos metodológicos, o método escolhido foi o indutivo. Quanto à finalidade, trata-se de uma pesquisa de ordem básica, que segundo Barros e Lehfeld (2014) tem como objetivo gerar conhecimento que seja útil para a ciência e tecnologia, sem necessariamente haver uma aplicação prática ou para obtenção de lucro. E nesse estudo, buscou-se contribuir para o entendimento da identidade gastronômica da praia do Tupé segundo a percepção dos permissionários dessa praia. Em relação aos fins é uma pesquisa descritiva onde se buscou traçar o perfil dos permissionários que exploram a gastronomia na referida praia e relatar as características gerais da

\footnotetext{
${ }^{4}$ Gourmetização é o processo intencional de sofisticação e exclusividade de um produto, uma forma de diferenciar o que é preparado de modo tradicional, relacionando um produto com a ideia de requinte. (PALMIERI JÚNIOR, 2017).
} 
gastronomia cultural do local segundo a percepção desses sujeitos. Trata-se ainda, de pesquisa explicativa ao analisar se a gastronomia local representa a identidade gastronômica do Amazonas, e descrever as dificuldades que esses permissionários encontram para preparar a gastronomia local (RICHARDSON, 1999).

Quanto aos meios a pesquisa em primeiro momento se classifica como bibliográfica, pois foi realizado um levantamento em livros, monografias e artigos sobre a temática gastronomia e depois de campo com observação e coleta de dados in loco. (FACHIN, 2006). Os sujeitos de pesquisa foram os permissionários das barracas da praia. A coleta foi realizada por meio da observação e o instrumento de pesquisa foi o formulário com perguntas abertas e fechadas. A coleta de dados ocorreu nos meses de abril e maio de 2018 (somente nos finais de semana).

Trata-se de um estudo de caso, em que as pesquisadoras extraíram as informações com a observação direta e com uma participação de cinco sujeitos pesquisados. Dos sete permissionários, dois deles não trabalham com alimentação, e por este motivo não foram entrevistados. Considera-se permissionários os comerciantes que possuem permissão para venda de produtos alimentícios nas barracas. Para realizar a pesquisa de campo o projeto de pesquisa teve que ser submetido a análise pelo órgão gestor - Secretaria Municipal de Meio Ambiente e Sustentabilidade (SEMMAS), e após autorização expressa, foi realizado.

A coleta de dados foi realizada por meio de formulário com perguntas abertas e fechadas. Ele foi aplicado aos cinco dos sete permissionários das barracas (sujeitos da pesquisa) pelas pesquisadoras, na praia do Tupé. Todos os cinco optaram por responder e assinar o termo de consentimento (TCLE). O instrumento de coleta foi dividido em três partes: dados de identificação para traçar o perfil dos permissionários; dados gerais da gastronomia sobre conhecimento, elaboração e preparo das iguarias; e dificuldades dos permissionários. Os dados foram analisados qualitativamente relacionado o marco teórico com os dados coletados e quantitativamente considerando a frequência das respostas nas questões fechadas. 


\section{APRESENTAÇÃO E ANÁLISE DOS RESULTADOS}

Ao traçar o perfil dos permissionários da RDS do Tupé, chegou-se aos seguintes resultados: quanto ao gênero, são 3 permissionários do sexo feminino e 2 do sexo masculino. Quanto a faixa etária, 1 respondente está na faixa de 50 a 54 anos, 1 na faixa de 55 a 59 anos, 2 respondentes estão na faixa de 60 a 64 anos, e 1 respondente está na faixa de 65 a 69 anos.

Quanto a escolaridade, o resultado encontrado foi de $80 \%$ dos permissionários (4 respondentes) não concluíram o ensino fundamental e apenas 20\% (1 permissionário) conseguiram concluir o ensino médio. Observou-se que uma das características dos povos tradicionais de comunidades ribeirinhas é que devida a dificuldade financeiras sempre se faz a opção por deixar os estudos para ir ao trabalho para ajudar no sustento da família.

Traçando o perfil do perfil dos permissionários, detectou-se que dois (40\%) respondentes estão na condição de permissionários de 2 a 4 anos, um (20\%) de 4 a 6 anos, e dois (40\%) há mais de 12 anos. Vale destacar que um deles afirmou que já trabalha na praia há mais de 30 anos, antes mesmo das barracas serem construídas.

Geralmente as famílias das comunidades são bem numerosas, no entanto identificou-se que os permissionários dividem a casa com no máximo até 6 pessoas. Sendo que um é solteiro. Três moram com 2 a 3 pessoas e um mora com 4 a 6 pessoas. Com exceção do respondente solteiro, $80 \%$ dos permissionários responderam que todos os moradores da casa ajudam nos trabalhos das barracas. Atualmente nenhum deles tem um trabalho remunerado formal. Identificou-se que quatro (80\%) dos permissionários já tiveram outra ocupação remunerada e apenas um (20\%) respondeu que não teve outra ocupação.

Pode-se notar que a origem da maioria dos permissionários $(80 \%)$ é da comunidade de São João do Tupé e apenas um (20\%) é do município de Manaus. Apesar das barracas serem destinadas especialmente aos comunitários da RDS do Tupé, houve uma exceção que permitiu que uma pessoa de outro município pudesse participar da seleção para posse de uma das barracas da praia do Tupé.

A respeito das características gerais da gastronomia constatou-se que as opções de pratos ofertados nas barracas a iguaria peixe e frango é vendida por 4 dos 5 
permissionários. A carne bovina é vendida em todas as barracas, sendo que uma delas usa exclusivamente a proteína de carne vermelha, não trabalha com carne branca no cardápio. Quanto as guarnições, todos os permissionários ofertam baião de dois, farofa e vinagrete, ficando exclusivo à uma barraca apenas, a guarnição extra (macarrão e maionese). Observa-se que os cardápios ofertados nas barracas são muito parecidos. A única barraca que vende exclusivamente carne bovina, também é a única que oferece sobremesas como bolos, doces e sucos naturais.

Todos os permissionários compram os insumos necessários para fazer os pratos servidos, não sendo o cultivo um hábito na comunidade. "Compramos tudo em Manaus, a terra na comunidade é muito ruim", relatou um permissionário. Nesse contexto, dos 5 permissionários apenas um se mostrou interessado em cultivar seus próprios legumes, verduras e frutas, e sobre isso, afirmou que já vem preparando a terra de uma pequena horta. Identificou-se que diferentemente do que descreve Santos (2010, p. 28), quando diz que os povos tradicionais do Amazonas eram praticantes do cultivo, observa-se no caso estudado que com as mudanças da contemporaneidade cada vez mais se perde a essência cabocla.

Quanto às bebidas, apenas um dos permissionários (20\%) oferta sucos naturais além dos produtos industrializados. Os demais (80\%) preferem vender apenas água, refrigerantes e cervejas. Conforme os dados obtidos, é perceptível que em relação às bebidas, os permissionários ainda precisam se apropriar mais das frutas regionais, uma vez que no Amazonas há uma diversidade de frutos que podem ser usados na preparação de sucos, cremes, geleias e doces, que podem ser adicionados ao cardápio e diversificá-lo ainda mais.

Quanto ao prato mais pedido pelos turistas e visitantes, o tambaqui assado é o mais solicitado com $60 \%$ dos pedidos, seguido pelo churrasco de carne, que responde por $40 \%$ dos pedidos. Sendo assim, identifica-se que o peixe ainda é mais solicitado pelos turistas e visitantes. Vale ressaltar que o peixe é um elemento marcante da culinária Amazônica. É importante lembrar que os pratos selecionados como mais pedido geralmente são servidos acompanhados de baião de dois, farofa (ou farinha pura) e vinagrete, que formam um prato muito característico da região.

Enfatizado por $100 \%$ dos permissionários, nenhum visitante pede para mudar nada no cardápio, exceto quando os pais pedem para tirar o vinagrete já que será servido 
para criança. Um fato importante é a possibilidade de antecipar o pedido, feito pelos banhistas que vão em lancha (Iate), conforme relato de um dos sujeitos de pesquisa: "eles ligam e encomendam a caldeirada de peixe, dizem a hora que vão chegar e quantas pessoas vão comer".

Três dos permissionários preparam as comidas em suas casas, e 2 responderam que preparam na própria barraca. De acordo com uma das permissionárias, não têm como preparar os alimentos nas barracas pelo fato de não haver água encanada e nem pia. Entretanto, impende ressaltar que, por estarem utilizando uma estrutura improvisada, alguns levam fogão a gás e já trazem algumas guarnições previamente preparadas para apenas finalizarem na barraca. Todos os permissionários responderam terem realizados cursos de capacitação ofertados pela SEMMAS.

Em relação aos insumos, a pesquisa demonstrou que todos os permissionários adquirem a carne bovina, verduras e temperos em outros municípios. Já os itens peixes e frango $80 \%$ precisam comprar de outras comunidades ou município, sendo interessante destacar que apenas esporadicamente utilizam o peixe comprado na própria comunidade para vender nas barracas. A respeito das bebidas, $80 \%$ compram em outro município refrigerante, cerveja e água mineral. Apenas uma permissionária utiliza os frutos maracujá e cupuaçu cultivados por ela mesma. Conforme visto anteriormente, observa-se que existe uma certa dificuldade dos permissionários para adquirirem os produtos que são usados na preparação das comidas, pois eles precisam ir ao município de Manaus fazer a compra dos insumos necessários.

No que diz respeito a cultura gastronômica, ao serem questionados sobre quais os produtos consideram como amazônicos, os permissionários não sabiam responder. Após intervenção e explicação com exemplos, todos responderam ser o peixe o produto que mais representa a culinária amazonense. Identificou-se que três $(60 \%)$ afirmaram que o tambaqui assado pertence a culinária do Amazonas, enquanto um (20\%) indicou o escabeche de peixe, e outro permissionário (20\%) afirmou que o peixe frito com baião de dois pertence a culinária amazônica. Analisando as respostas dos permissionários compreende-se que em visões parecidas, todos identificam o peixe como identidade marcante pertencente a gastronomia regional, e que independentemente dos diferentes modos de preparo, é um item característico da gastronomia da região Amazônica. 
Uma análise das respostas permitiu perceber o que os barraqueiros entendem como 'culinária regional' o peixe e ele aparece como uma forte representação da identidade culinária amazonense, em sua variedade tanto de espécimes quanto de formas de preparo. Mesmo não conceituando, os permissionários conseguiram exemplificar claramente como o peixe é um forte símbolo dessa identidade cultural.

Conclui-se que, apesar da falta de compreensão em relação à questão cultural, os mesmos possuem uma concepção própria de identificação da culinária regional do Amazonas. Embora os mesmos ignorem que essa concepção seja construída a partir de fatores externos, esses mesmos fatores já estão enraizados em sua cultura.

A última parte da pesquisa abordou a percepção dos permissionários em relação às quatro afirmativas disponíveis no quadro a seguir, respondidas de acordo com o grau de sua concordância dos respondentes.

QUADRO 1 - RESPOSTAS DOS PERMISSIONÁRIOS SOBRE A GASTRONOMIA REGIONAL

\begin{tabular}{|l|c|c|c|c|c|}
\hline \multicolumn{1}{|c|}{ SENTENÇA AFIRMATIVA } & $\mathbf{1}$ & $\mathbf{2}$ & $\mathbf{3}$ & $\mathbf{4}$ & $\mathbf{5}$ \\
\hline 1) Considero que vendo produtos da culinária regional. & & & & & $100 \%$ \\
\hline 2) Utilizo somente produtos típicos da região. & & & $20 \%$ & $20 \%$ & $60 \%$ \\
\hline 3) Pesquiso sobre produtos regionais. & $60 \%$ & & & $40 \%$ & \\
\hline $\begin{array}{l}\text { 4) Acredito que a venda de produtos regionais valoriza a } \\
\text { preservação da cultura local. }\end{array}$ & & & $20 \%$ & & $80 \%$ \\
\hline $\begin{array}{l}\text { 5) Uso somente frutos regionais no preparo de sucos e } \\
\text { sobremesas. }\end{array}$ & $80 \%$ & & & & $20 \%$ \\
\hline $\begin{array}{l}\text { 6) Compro doces, geleias e biscoitos de outras } \\
\text { comunidades da RDS do Tupé, para revender como } \\
\text { sobremesas na barraca. }\end{array}$ & $100 \%$ & & & & \\
\hline $\begin{array}{l}\text { 7) Sempre dou ouvidos às sugestões dos turistas e } \\
\text { visitantes sobre outros pratos típicos da culinária. }\end{array}$ & $40 \%$ & & & & $60 \%$ \\
\hline
\end{tabular}

FONTE: Dados da Pesquisa (2018).

Conforme visto no Quadro 1 percebe-se que 100\% dos permissionários consideram que vendem produtos regionais, mesmo que esses produtos em sua maioria sejam representados pelo peixe. Dessa forma, compreende-se que pelo fato dos produtos serem comprados em Manaus, os mesmos acabam por acreditar que tais sejam da região do estado do Amazonas. Nas barracas gastronômicas o prato que mais representa a 
região é a banda de tambaqui assado servida com baião de dois, vinagrete e farinha (ou farofa). Ainda há uma fragilidade, pois nos pratos ofertados não representam a gastronomia regional ou local e tem $80 \%$ de suas bebidas industrializadas, como o refrigerante e a cerveja.

Percebeu-se ainda, que $60 \%$ dos permissionários entendem que utilizam apenas produtos típicos da região, porém para eles o ato de comprar produtos em Manaus significa que são produtos típicos, mas na verdade muitas vezes compram muitos produtos industrializados, o que demonstra a ausência de identidade e conhecimento dos permissionários sobre os produtos regionais. Ao serem questionados se pesquisam sobre produtos regionais, $60 \%$ dos permissionários afirmaram que não. Como já abordado, também é baixa a utilização de frutas regionais para sucos, sorvetes e sobremesas.

Ainda sobre o Quadro 1, levantou-se que 100\% dos permissionários não tem o hábito de comprar doces, geleias e biscoitos de outras comunidades da RDS para revenda. E, 60\% dos entrevistados procuram atender as sugestões dos turistas que frequentam a praia, contrapondo-se a $40 \%$ dos permissionários que se opõem totalmente a qualquer tipo de mudança.

As principais dificuldades dos permissionários levantadas pela pesquisa foram:

a) No tocante ao manejo para a preparação dos alimentos, uma vez que não há água encanada e pia nas barracas, havendo a necessidade de preparação antecipada em suas respectivas casas, levando os alimentos já praticamente prontos;

b) A logística para a compra dos insumos, em virtude da necessidade de deslocamento até Manaus para aquisição dos produtos, o que é dispendioso;

Observou-se um baixo nível educacional acadêmico e isso se refletiu em algumas respostas. Todavia, a análise das respostas permitiu perceber o que os permissionários entendem como 'culinária regional', o peixe, e que ele é apresentado como representação da identidade culinária amazonense, em sua variedade tanto de espécimes quanto de formas de preparo. Mesmo não conceituando, os permissionários conseguiram exemplificar claramente como o peixe é um forte símbolo dessa identidade cultural. Apesar da falta de conhecimento técnico e científico, eles possuem uma concepção própria de identificação da culinária regional do Amazonas. 


\section{CONSIDERAÇÕES FINAIS}

O objeto dessa pesquisa teve como foco a identidade da culinária oferecida na praia do Tupé, que está inserida na Reserva de Desenvolvimento Sustentável (RDS) do Tupé e foi atendido ao realizar a pesquisa de campo com permissionários que comercializam alimentos e bebidas na praia. Comer é uma das formas de se conectar à cultura de certo povo. Por isso é importante que os permissionários utilizem a comercialização de comidas e bebidas para apresentar a gastronomia regional. Eles devem conhecer e saber quais os produtos que realmente representem a localidade, mas observando quais os produtos que mais agradam aos consumidores.

A partir dos resultados alcançados, pode-se traçar o perfil dos permissionários, e assim compreender a forma de trabalho utilizada. Foi identificada também pouca identidade com outros produtos regionais além do peixe, o que pode se dar em virtude da baixa escolaridade e falta de interesse em pesquisas e conhecimentos sobre os produtos regionais. Segundo a percepção dos permissionários, em que pese servirem carne bovina e frango, entendem ser o peixe, de todos os alimentos servidos, o que representa a gastronomia regional da Amazônia.

Considerando o perfil dos permissionários foi observado o pouco conhecimento sobre os produtos regionais que podem ser utilizados no manejo dos alimentos, bem como as dificuldades elencadas pelos mesmos, como falta de infraestrutura e logística para compra dos insumos. São necessários investimentos em infraestrutura e fortalecimento da identidade cultural com outros produtos regionais, especialmente frutas e especiarias, posto que há poucas opções de pratos típicos nos cardápios disponibilizados aos visitantes.

Outro investimento necessário é no tocante às técnicas de manuseio e oferta dos alimentos, visando a melhoria do serviço gastronômico como um todo. Sugere-se ainda, cursos aos permissionários para que tenham uma maior compreensão sobre as comidas típicas amazônicas, gerando um maior sentimento de pertencimento com a cultura gastronômica local, o que, certamente importará em melhores serviços e produtos turísticos.

Os resultados da pesquisa contribuem para que a Secretaria Municipal de Meio Ambiente e Sustentabilidade (SEMMAS) órgão gestor da Unidade de Conservação, a 
sociedade amazonense e os comunitários das comunidades da RDS e a Fundação Municipal de Cultura, Turismo e Eventos (Manauscult), trabalharem a gastronomia da Praia do Tupé com vistas valorização da sua cultura e a oferta de um produto mais atraente para o turista. Do ponto de vista acadêmico, a presente pesquisa se torna relevante uma vez que poderá cooperar para novas discussões sobre gastronomia local do Amazonas.

É importante destacar que a venda de comida e bebida na praia é permitida exclusivamente pelos permissionários. Entende-se que poderia ser desenvolvido um projeto de ampliação do cardápio, com a utilização de produtos regionais, e divulgação da praia e de seus atrativos culinários. Deve-se dar atenção ao marketing do atrativo, mostrando não somente as belezas naturais, mas também a gastronomia local.

Como limitação da pesquisa não foi possível analisar a percepção de outros comunitários e gestores da SEMMAS e Manauscult sobre a importância da gastronomia para o desenvolvimento turístico na comunidade. Sugere-se para pesquisas futuras uma análise que confronte as expectativas gastronômicas dos turistas e visitantes com as visões dos permissionários sobre a satisfação dos serviços oferecidos.

\section{REFERÊNCIAS}

ANDRADE. B. L. S. de. Gourmet e a atratividade turística: ressignificações da gastronomia regional de fortaleza/ce . $121 \mathrm{f}$. Dissertação (Mestrado Profissional em Gestão de Negócios Turísticos) - Universidade Estadual do Ceará, Fortaleza, 2018.

ANSARAH, M. G. dos R.; NUNES, C. Hospitalidade nos serviços de alimentação como diferencial na prestação de serviços, 2007. Santos. Anais... Santos: VII Encontro dos Núcleos de Pesquisa em Comunicação - NP Comunicação, Turismo e Hospitalidade, 2007.

ARAÚJO, W.M.C.; BOTELHO, R. B. A.; GINANI, V. C.; ARAÚJO, H. M. C.; ZANDONADI, R. P. Da alimentação a gastronomia. Brasília: UNB, 2005.

AZEVEDO, E. A. DE; SILVEIRA, F. A. DA. A gastronomia como elemento do produto turístico - caminhos possíveis para a diversificação da oferta turística em São Cristóvão - SE. Ponta de Lança: Revista Eletrônica de História, Memória \& Cultura, v. 10, n. 19, p. 73 - 91, 27 fev. 2018.

BARROCO, L., BARROCO, H., A Importância da Gastronomia como Patrimônio Cultural, no Turismo Baiano. Revista TURyDES v. 1, n 2, não paginado, 2008. 
BARROS, A. J. da S.; LEHFELD, N. A. de S. Fundamentos de Metodologia científica. 5. ed. São Paulo: Pearson Prentice Hall, 2014.

BOER, L. de; REJOWSKI, M. Dimensões da Hospitalidade em um Restaurante Comercial. Turismo e Sociedade. v. 9, n. 1, p. 1-23, 2016.

BRAGA, V. Cultura Alimentar: contribuições da antropologia da alimentação. Saúde em Revista. Piracicaba, v.6, n.13, p. 37-44, 2004.

BRASIL. Ministério da Cultura. Aromas, cores \& Sabores do Brasil. Brasília: Ministério da Cultura. 2013. Disponível em: http://www.copa2014.gov.br/sites/default/files/livreto_web17062013.pdf. Acesso em: 20 abr. 2018.

BRAUNE, R.; FRANCO, S. O que é Gastronomia. São Paulo (SP): Brasiliense, 2013.

CLEMENT, R. S.; FALCÃO, M. A.; SOUZA, M. de N. P. de. O Sabor do Amazonas. Governo do Estado do Amazonas - Secretaria de Estado de Cultura. Manaus 2010.

Disponível em: < http://www.sumauma.net/amazonian/sabor/sabordoamazonas.html>. Acesso em 20 abr. 2020.

DANTAS, M. Tradicional café regional ainda é preferência no domingo, em Manaus. G1 Amazonas. 06 de jan. de 2013. Disponível em: $<$ http://g1.globo.com/am/amazonas/noticia/2013/01/tradicional-cafe-regional-ainda-epreferencia-no-domingo-em-manaus.html>. Acesso em: 20 fev. 2018.

DENTZ, B. G. Z. V. Identidade Gastronômica Alemã em Águas Mornas - SC: Um Estudo Para o Fortalecimento do Turismo de base Local. Dissertação (Mestrado em Planejamento e Gestão do Turismo e da Hotelaria) - Centro de Ciências Sociais Aplicada - Comunicação, Turismo e Lazer (CECIESA), Universidade do Vale do Itajaí, Balneário Camboriú 2011.

FACHIN, O. Fundamentos de Metodologia. 5 ed. São Paulo: Saraiva, 2006.

GIMENES, M. H. S. G. O uso turístico das comidas tradicionais: algumas reflexões a partir do Barreado, prato típico do litoral paranaense (Brasil). Turismo e Sociedade, v. 2, n. 1, p. 8-24, 2009.

. Patrimônio Gastronômico, Patrimônio Turístico: uma reflexão introdutória sobre a valorização das comidas tradicionais pelo IPHAN e a atividade turística no Brasil, 2006. Caxias do Sul. Anais... Caxias do Sul: IV Seminário de Pesquisa e Turismo do MERCOSUL, 2006.

GIMENES-MINASSE, M. H. S. G. A Gastronomia brasileira na Copa do Mundo de Futebol da FIFA 2014: uma breve análise. Turismo e Sociedade. v. 7, n. 1, p. 77-98, 2014. 
Notas sobre políticas públicas a respeito da gastronomia no contexto turístico brasileiro. Turismo e Sociedade. v. 9, n. 3, p. 1-18, 2016.

HENRIQUES, C.; CUSTÓDIO, M. J. Turismo E Gastronomia: a valorização do património gastronómico na região do Algarve. Tourism \& Management Studies, $n$. 6, p. 69-81, 2010.

HIGASHI, L. N. S.; MARTINS, C. A. de M. G. A Importância da Gastronomia para o Turismo Local. 19 f. Artigo (Especialização em Eventos) - Escola Superior de Artes e Turismo (ESAT), Universidade do Estado do Amazonas, Manaus, 2013.

MOURA, J. B. Mapeamento dos custos para tarifa de transporte no trecho Manaus - Barcelos: um estudo de caso. Dissertação (Mestrado em Engenharia de Produção), Universidade Federal do Amazonas, Manaus, 2017.

MÜLLER, S. G. Patrimônio cultural gastronômico: identificação, sistematização e disseminação dos saberes e fazeres tradicionais. Tese (Doutorado em Engenharia e Gestão do Conhecimento), Universidade Federal de santa Catarina, Florianópolis, 2012.

PALMIERI JÚNIOR, V. A gourmetização em uma sociedade desigual: um estudo sobre a diferenciação no consumo de alimentos industrializados no Brasil. 2017. $224 \mathrm{f}$. Tese (Doutorado em Desenvolvimento Econômico) - Instituto de Economia, Universidade Estadual de Campinas, Campinas, 2017.

PORTAL AMAZÔNIA. Pesquisa revela qual é o peixe mais consumido por moradores de Manaus. Atualizado em 16 de fev. 2020. Disponível: <

https://portalamazonia.com/noticias/pesquisa-revela-qual-e-o-peixe-mais-consumidopor-moradores-de-manaus>. Acesso em: 19 mar. 2020.

PÉREZ, X. P. Turismo Cultural. Uma visão antropológica- El Sauzal: ACA y PASOS, RTPC. 2009. Disponível em:

$<$ http://www.pasosonline.org/Publicados/pasosoedita/PSEdita2.pdf $>$. |Acesso em 16 mar. 2018.

QUINZANI, S. S. P.; CAPOVILLA, V. M.; CORRÊA, A. A. S. A pluralidade gastronômica da região amazônica: sabores acreanos, paraenses e do alto rio negro.

Revista Hospitalidade, n.2, v. 13, p. 248-271, 2016.

RICHARDSON, R. J.; PERES, J. A. S. Pesquisa social: métodos e técnicas. 3. ed. São Paulo: Atlas, 1999.

RODRIGUES, E. B.; OLIVEIRA, J. de S.; SOUSA, J. O. de; ABREU, D. do N.; LIMA, F. dos S. A experiência gastronômica a bordo de um cruzeiro pela costa brasileira: Uma viagem do paladar. Revista Científica Digital - Jornalismo,

Publicidade e Turismo. n.1, v.1, p.1-16, 2015. 
SANTOS, R. I. C. dos S.; ANTONINI, B. O. La gastronomía típica de la isla de Santa Catarina, Brasil - Su identidad como atractivo para el turismo cultural. Estudios y perspectivas em turismo. v. 13, n 1 y 2, p.89-110, 2004.

SILVA, P. P. Farinha, feijão e carne-seca: um tripé culinário no Brasil colonial. São Paulo: Editora SENAC São Paulo, 2005.

SCHLÜTER, R. G. Gastronomia e Turismo; tradução: Roberto Sperling - (Coleção ABC do turismo). São Paulo: Aleph, 2003.

VERGARA, S. C. Projetos e relatórios de pesquisa em administração. 16 ed. São Paulo: Atlas, 2017.

Recebido em: 20-10-2019.

Aprovado em: 02-05-2019. 